Published in final edited form as:

Future Cardiol. 2009 January ; 5(1): 93-103. doi:10.2217/14796678.5.1.93.

\title{
Estrogen, aging and the cardiovascular system
}

\author{
James P. Stice, \\ Molecular \& Cellular Cardiology, University of California, Davis, One Shields Avenue, Davis, CA \\ 95616, USA, Tel.:+1 530752 5501, Fax: +1 5307547167 \\ Jennifer S. Lee, \\ Endocrinology Division, University of California, Davis, Medical Center, Sacramento, CA 95817, \\ USA, Tel.: +1 916734 3764, Fax: +1 9167348394
}

Angela S. Pechenino, and Molecular \& Cellular Cardiology, University of California, Davis, One Shields Avenue, Davis, CA 95616, USA, Tel.: +1 530752 9717, Fax: +15307547167

Anne A. Knowlton ${ }^{\dagger}$

Molecular \& Cellular Cardiology, University of California, Davis, One Shields Avenue, Davis, CA 95616, USA, Tel.: +1 530752 5461, Fax: +15307547167

James P. Stice: jpstice@ucdavis.edu; Jennifer S. Lee: jswlee@ucdavis.edu; Angela S. Pechenino: aspechenino@ucdavis.edu; Anne A. Knowlton: aaknowlton@ucdavis.edu

\section{Abstract}

Estrogen is a powerful hormone with pleiotropic effects. Estrogens have potent antioxidant effects and are able to reduce inflammation, induce vasorelaxation and alter gene expression in both the vasculature and the heart. Estrogen treatment of cultured cardiac myocytes and endothelial cells rapidly activates NFkB, induces heat-shock protein (HSP)-72, a potent intracellular protective protein, and protects cells from simulated ischemia. In in vivo models, estrogens protect against ischemia and trauma/hemorrhage. Estrogens may decrease the expression of soluble epoxide hydrolase, which has deleterious effects on the cardiovascular system through metabolism of epoxyeicosatrienoic acids. Natural (endogenous) estrogens in premenopausal women appear to protect against cardiovascular disease and yet controlled clinical trials have not indicated a benefit from estrogen replacement postmenopause. Much remains to be understood in regards to the many properties of this powerful hormone and how changes in this hormone interact with agingassociated changes. The unexpected negative results of trials of estrogen replacement postmenopause probably arise from our lack of understanding of the many effects of this hormone.

\footnotetext{
(C) 2009 Future Medicine

${ }^{\dagger}$ Author for correspondence: Molecular \& Cellular Cardiology, University of California, Davis, One Shields Avenue, Davis, CA 95616, USA Tel.: +1 5307525461 Fax: +1 5307547167 aaknowlton@ucdavis.edu.

Financial \& competing interests disclosure

Anne A Knowlton is supported by the Department of Veterans Affairs. James P Stice is supported by the American Heart Western States Affiliate. Jennifer S Lee is supported by UL1 RR024146 from the National Center for Research Resources (NCRR), the Fannie E Rippel Foundation, and the American Federation of Aging Research. The authors have no other relevant affiliations or financial involvement with any organization or entity with a financial interest in or financial conflict with the subject matter or materials discussed in the manuscript. This includes employment, consultancies, honoraria, stock ownership or options, expert testimony, grants or patents received or pending, or royalties.

No writing assistance was utilized in the production of this manuscript.
} 


\section{Keywords}

aging; endothelial cells; estrogen; hormone-replacement therapy; menopause; NFkB; soluble epoxide hydrolase

In the cardiovascular system, estrogens exert powerful antioxidant effects, attenuate inflammation, induce vasorelaxation and activate the prosurvival phosphatidylinositol 3kinase (PI3-K)/Akt pathway [1]. The effect of these changes leads to a decrease in cardiovascular disease and protection against ischemia/reperfusion, myocardial infarction and trauma/hemorrhage injury [2,3]. Overall, premenopausal women have a lower incidence of cardiovascular disease (CVD) compared with postmenopausal women, and this is at least in part due to the effect of estrogens [4]. However, many of the effects of estrogens remain to be elucidated. Complex interactions of estrogen with inflammatory processes and protective cellular responses are emerging as novel areas for new therapeutic targets. Difficulties in interpreting whether hormone-replacement therapy (HRT) is beneficial are due to variations among basic and clinical studies. In this review we focus on basic science studies on the effects of estrogen, which we integrate with an examination of the clinical data on HRT use in postmenopausal women.

\section{Vascular aging}

Changes in the vasculature that occur with age include widening and elongation of large arteries, increased intima-media thickening, stiffening of the vessels and endothelial dysfunction. These changes have been extensively reviewed elsewhere and are outlined in Figure 1 [5]. Studies have primarily focused on male models. The fundamental age-related change in arterial function is a reduction in vascular relaxation, which is associated with an increase in pulse wave velocity [5]. Several different mechanisms have been proposed to account for the abnormal relaxation in aged male models. In males, age-related decreases in vascular relaxation are characterized by a reduction in the nitric oxide (NO)-dependant vasodilator response to acetylcholine (ACh) [6]. This impaired response to Ach is thought to be primarily due to downregulation in the activation and expression of endothelial NO synthase (eNOS) [7]. In addition, aging has been reported to increase arginase I activity, endothelial cell susceptibility to apoptosis and the generation of reactive oxygen species (ROS), such as superoxide and peroxynitrate, all of which decrease NO bioavailability [5,8]. Changes within the vascular smooth muscle (VSM) that occur with age also impair vasodilation. Aging has been reported to downregulate the NO receptor, soluble guanylyl cyclase (sGC), as well as decrease PKG activation in adult male rat aortas [9-11]

\section{Estrogen, aging \& the endothelium}

In animal models, ovariectomy (OVX) leads to an enhanced sensitivity to vasoconstrictive agents and impaired vasorelaxation. Loss of estrogens increases phenylephrine and angiotensin (Ang) II vasoconstriction through the upregulation of the ang II type I receptor, which can be reduced by supplementation with $17 \beta$-estradiol $\left(\mathrm{E}_{2}\right)$, the most biologically active form of estrogen $[12,13]$. In addition to the increased constrictive response, loss of estrogens, similar to aging, impairs vasorelaxation in response to ACh $[6,14,15]$. The impairment is thought to be due to a decrease in eNOS expression along with NO bioavailability and can be partially restored by $\mathrm{E}_{2}$ replacement. It is interesting to note that we found no change in eNOS expression or NO levels in old ovariectomized Norway Brown (NB) rats, but decreased NO-receptor levels in the VSM as discussed below. The loss of estrogens also increases endothelial cell apoptosis, which can be reversed by $E_{2}$ replacement [16]. OVX inhibits the generation of other vasorelaxants, such as endothelium-derived hyperpolarizing factor, which can similarly impair vasorelaxation $[17,18]$. 
The loss of compliance with age partially accounts for the increased risk for cardiovascular diseases such as hypertension and atherosclerosis [19]. In the adult endothelium, $\mathrm{E}_{2}$ can partially slow progression towards these diseased states. In rat mesenteric arteries, Ang II, a proinflammatory and potent vasoconstrictor, induces leukocyte rolling flux, adhesion and emigration [20]. Administration of $\mathrm{E}_{2}$ inhibited angiotensin II-induced leukocyteendothelial cell interactions through endothelial NO synthase and prostacyclin release via cyclooxygenase activation. $E_{2}$ is also shown to abrogate the expression of adhesion molecules in the endothelium in proinflammatory states and has been extensively reviewed elsewhere [21,22]. It is not known whether $\mathrm{E}_{2}$ exerts these same effects in aged endothelium.

\section{Estrogen, aging \& the smooth muscle}

Changes within the smooth muscle also contribute to reduced vascular relaxation in menopausal models. Using both adult (5 month) and aged ( 21 month) NB rats with and without $E_{2}$ replacement, we have recently demonstrated that the loss of estrogens in aged OVX rats leads to decreased endothelium-independent relaxation and decreased expression of the NO receptor sGC [15]. No changes were observed in eNOS or inducible NOS expression or in total circulating NO levels. Decreased expression of sGC in the aged OVX group changes could be corrected with $\mathrm{E}_{2}$ replacement. Use of a sGC agonist restored normal relaxation [15]. These results, which are summarized in Figure 2, suggest that sGC agonists are a potential new therapeutic approach for treatment of hypertension in elderly female patients.

\section{Estrogen, aging \& the extracellular matrix}

Aging in males leads to increased extracellular matrix deposition and vessel stiffness, but the effect of aging versus hormonal changes in females has not been well characterized. In vitro $\mathrm{E}_{2}$ treatment decreases collagen production [23] and increases the elastin:collagen ratio in cultured VSM cells. $E_{2}$ replacement in adult OVX Sprague-Dawley (SD) rats increases arterial distensibility [24]. Qui et al. found that aortic stiffness increases to a greater degree in aged male monkeys compared with aged female pre-menopausal and perimenopausal (characterized by irregular cycling) monkeys. Decreases in collagen type 3 and elastin along with an increase in collagen type 8 in the aged males probably accounted for the increase in aortic stiffness as compared with aged females [25]. The underlying mechanisms mediating abnormal vascular function with aging remains controversial and further work needs to be completed in order to understand how estrogen impacts the progression of impaired vascular function with age.

Interpretation of changes in the vasculature that occur with aging and the effect of estrogens is hampered by differences in the species and age of the animal models used, along with the duration, preparation and concentrations of $\mathrm{E}_{2}$ given. It is important that appropriately aged models, such as NB or Fisher 344 rats, neither of which develop obesity with aging, be used to appropriately model the changes of estrogen. Loss of ovarian function in rats begins around 18 months of age and complete loss can be noted around 2 years [26]. Animal studies using hormone replacement, which are to have clinical applications in postmenopausal populations, must use models that have entered this transition into loss of ovarian function. Too frequently, sexually immature rats ( $\leq$ months) are used to study the effects of estrogen loss; it is difficult to interpret these studies and to incorporate their findings into our understanding of the effects of aging versus loss of estrogen on the cardiovascular system. In order to understand changes in sexually mature rat models, we believe that rats must be a minimum of $4-5$ months old for adults and at least 18 months for aging studies. In addition, inbred models, such as the spontaneously hypertensive rats (SHR) 
are complicated by genetic changes that are not fully defined, making the literature using these models in aging more difficult to interpret.

\section{Estrogen \& the myocardium}

Estrogen withdrawal in adult female rat models leads to left ventricular (LV) hypertrophy, collagen I deposition [27] and increased sensitivity to constrictive agents, such as Ang II $[27,28]$. These changes can be prevented by $E_{2}$ replacement and appear to be specific to estrogen receptor (ER)- $\beta$ [29]. At the cellular level, $10 \mathrm{nM} \mathrm{E}_{2}$ treatment can prevent Ang II or endothelin (ET)-1 induced hypertrophy in isolated, neonatal rat cardiomyocytes [30]. $\mathrm{E}_{2}$ also exerts protective effects in the prevention of cardiomyocyte apoptosis. Numerous studies have demonstrated that females experience less apoptotic cell death than agematched males [31]. $E_{2}$ replacement reduces infarct size and cardiomyocyte apoptosis in animal models of myocardial infarction and ischemia/reperfusion via activation of the PI3K/AKT pathway and inhibition of ROS generation $[32,33]$.

The loss of endogenous estrogen in rat models via OVX leads to inflammation, ROS generation and decreased expression of vasorelaxant genes (Figure 1). We assessed changes in myocardial gene expression in intact, OVX and OVX plus $\mathrm{E}_{2}$ replacement adult female $\mathrm{SD}$ rats by microarray. We found that OVX increased genes mediating inflammation (IL-6, $T N F$-a, SOCS2 and SOCS3), the ECM formation (collagen12a 1 and connexin 43) and apoptosis (caspase 3 and calpain). However, genes involved in vascular tone and adhesion (eNOS and $s G C$ ) were decreased [34]. To investigate whether similar changes were induced in an aging model, we performed a microarray study on 21-25-month old intact, OVX and OVX plus $E_{2}$ NB rats. Although the results are preliminary, similar to adult rats, old OVX displayed decreased gene expression of vasorelaxant genes ( $s G C$ and $e N O S$ ). However, gene expression patterns differed significantly from those seen in adult OVX SD with and without $\mathrm{E}_{2}$ (Unpublished Data). Further work needs to be completed in order to determine these differences in gene expression between young and old rats with and without $\mathrm{E}_{2}$ replacement. This highlights the complexity of the interaction between aging and $\mathrm{E}_{2}$ replacement and stresses the importance that aged models are essential to understand the effects of HRT in postmenopausal models.

\section{Estrogen, aging \& the myocardium}

Myocardial aging is associated with a myriad of changes, including left ventricular (LV) hypertrophy, increased myocardial stiffness, heart failure and atrial fibrillation. These have been extensively reviewed elsewhere [8]. By contrast, there are a limited number of studies addressing how aging affects the response to estrogen in the myocardium. In SHR, early $\mathrm{E}_{2}$ replacement attenuated the development of hypertension and heart failure, while in aged rats, which had already developed hypertension, $\mathrm{E}_{2}$ replacement did not prevent heart failure. OVX in the adult ( 3 months) and aged ( 23 months) rat models increased LV weight:body weight ratios, decreased ERa expression, and caused a shift in the ratio of myosin heavy chain a to $\beta$, which is an indication of cardiac hypertrophy. The $E_{2}$-mediated reduction in cardiac hypertrophy was lost with aging [35]. Similarly, $\mathrm{E}_{2}$ replacement in the young (3 months), but not aged (24 months), heart failure rat model SHHF/Mcc-fa ${ }^{\mathrm{cp}}$ reduced the increase in blood pressure, impairment in fractional shortening and shift in major histocompatibility complex $\alpha / \beta$ isoform expression caused by OVX [36]. These findings are interesting, but the SHR and SHHF/Mcc-fa ${ }^{c p}$ are selective genetic models. The findings in these genetic models committed to the development of cardiovascular disease give insights into disease mechanisms, but further work needs to be completed in order to understand if the blunting of $\mathrm{E}_{2}$ responsiveness with age occurs more generally. 


\section{Stress response, aging \& estrogen}

One of the most fundamental changes in myocardial aging is a rearrangement in the acute and chronic responses to stresses. It is well established that aging leads to a blunting in responses to $\beta$-adrenergic stimuli, not through a loss of receptor but from an impairment in postreceptor signaling [5,37]. Recently, aging has also been linked with increased activation of proinflammatory factors, such as $\mathrm{NF \kappa B}$, and decreased activation of protective cellular responses. The heightened activity of $\mathrm{NF \kappa B}$ can be partially explained by the increased production of ROS and cytokines [38,39]. Aging also leads to fundamental changes in protective responses, such as the heat-shock response. Heat-shock proteins (HSPs) act as molecular chaperones to ensure proper protein folding, as well as to stabilize protein structure during cell stress/injury. HSPs protect the heart from injury and are induced by ischemia, stretch and other stimuli in the heart [40].

\section{NFKB, HSPs, estrogen \& stress}

We have previously reported that adult female SD rats have higher levels of cardiac HSP-72 than age-matched males. Reduction of female cardiac HSP72 to that of males occurred at 9 weeks post-OVX, and in vivo $\mathrm{E}_{2}$ replacement prevented this decrease [41]. In isolated adult male cardiomyocytes, $100 \mathrm{nM} \mathrm{E}_{2}$ treatment rapidly activates $\mathrm{NF \kappa B}$ after 15 min leading to heat shock factor (HSF)-1 activation after $3 \mathrm{~h}$ and HSP-72 expression after $24 \mathrm{~h}$ [42]. $\mathrm{E}_{2}$ pretreatment conferred protection against hypoxia/reoxygenation $(\mathrm{H} / \mathrm{R})$ injury. Inhibition of $\mathrm{NF \kappa B}$, but not HSF-1, led to attenuation of $\mathrm{E}_{2}$ 's cytoprotective effects against $\mathrm{H} / \mathrm{R}$ injury, even though inhibition of either transcription factor negated the effects of $\mathrm{E}_{2}$ on HSP-72 expression [42]. Similar effects were seen in human male coronary artery endothelial cells, although the induction of NFkB, HSF-1 and HSPs occurred at 10 and $100 \mathrm{nM} \mathrm{E}_{2}$, reflecting increased sensitivity of endothelial cells to $\mathrm{E}_{2}$ [43]. $\mathrm{E}_{2}$ can both activate and inhibit $\mathrm{NFkB}$ depending on the duration of treatment and this has been reviewed elsewhere [44]. Acute activation of $\mathrm{NFKB}$ by $\mathrm{E}_{2}$ is protective and leads to the expression of antiapoptotic molecules and cytoprotective proteins. However, long-term $\mathrm{E}_{2}$ treatment can inhibit the prolonged activation of $\mathrm{NF \kappa B}$ that has been associated with numerous pathological conditions, such as atherosclerosis, rheumatoid arthritis and cancer.

Protective responses, such as the heat-shock response, have also been shown to decrease with age. It is noteworthy that there is a lack of production of the cytoprotective HSP-72 upon challenge with exercise, hyperthermia and hypoxia in aged male models $[45,46]$. The role of estrogen and aging on the heat-shock response in the myocardium has not been investigated. Using OVX adult (5 months) and aged (21 months) female NB rats with and without $\mathrm{E}_{2}$ replacement, we found similar basal expression of HSPs in isolated cardiomyocytes (vs intact heart where HSP-72 is more abundant in other cell types) [47]. Treatment with $100 \mathrm{nM} \mathrm{E}_{2}$ increased expression of HSP-72 and HSP-90 in the adult, but not in aged cardiomyocytes. Similarly, $100 \mathrm{nM} \mathrm{E}_{2}$ treatment activated $\mathrm{NFKB}$ in the adult but not in the aged myocytes. The loss of response to $\mathrm{E}_{2}$ with aging was not due to differences in ER- $\alpha$ or $\beta$ expression (UNPUBLISHED DATA). Further work needs to be completed in order to ascertain how the loss of the heat-shock response impacts CVD, and whether targeting this loss can attenuate the severity of heart disease in aging.

\section{Estrogen, soluble epoxide hydrolase \& cardiovascular injury}

$17 \beta$-estradiol may regulate an emerging novel therapeutic target against CVD - soluble epoxide hydrolase (sEH) [48]. Arachidonic acid is converted to endogenous lipid epoxides epoxy-eicosatrienoic acids (EETs), which sEH (the cytochrome P450 [CYP] eicosanoidsmetabolizing enzyme) degrades to 1,2-diols (dihydroxy-eicosatrienoic acids [DHETs]). High sEH levels decrease EETs and increase DHETs [49], whereas inhibitors of sEH increase the EETs to DHETs ratio in animal models [50]. EETs have numerous beneficial 
cardiovascular and anti-inflammatory actions in animal models. They decrease blood pressure and increase vasodilation [51] and reduce cardiac and brain ischemic injury [52]. EETs prevent leukocyte adhesion to the vascular wall by inhibiting NFKB [53], suppress hyperthermia and platelet aggregation [54], and decrease pain during inflammatory states [50].

\section{sEH \& cardiovascular insult}

Cumulative evidence from animal studies has demonstrated that $\mathrm{sEH}$ is an important player in responses to cardiovascular insults. Studies of sEH-null mice undergoing induced ischemia, with and without an EET inhibitor, illustrated that EETs are cardioprotective by promoting recovery of postischemic cardiac contractility [55]. SEH may, in part, explain $\mathrm{E}_{2}$ 's effects on NFKB; inhibitors of sEH block NFKB activation in murine cardiac myocytes and prevent and reverse cardiac hypertrophy [56]. The role of EETs and SEH on NFkB may serve as an additional checkpoint on uncurbed NFkB activation, which leads to chronic inflammation and apoptosis. SEH knockout mice with middle cerebral artery occlusion (MCAO) lacked DHET and had smaller infarct sizes with increased cerebral blood flow rates, presumably due to EET action, since these effects were abolished by adding an EET antagonist [57]. Furthermore, polymorphisms in EPHX2, the gene that encodes for sEH, have been associated with risks of stroke [52,58] and CHD [59-61] in human studies and hypertension in rat models [62].

As previously noted, the effects of $E_{2}$ on inflammation in the cardiovascular system may, in part, be due to $\mathrm{E}_{2}$ 's regulation of $\mathrm{sEH}$. OVX rats with MCAO experience $\mathrm{E}_{2}$ 's neuroprotection against inflammation, which is explained, in part, by regulation of cerebral sEH by $E_{2}$ [63]. In OVX rats, physiological $E_{2}$ replacement reduced basal and postischemic cerebral sEH expression and diminished inflammation after MCAO. However, inflammation was not attenuated by sEH inhibitors and $\mathrm{E}_{2}$ replacement produced an early increase followed by a delayed decrease in cytokine mRNA expression [63]. Female C57B/6 mice have a lower expression of sEH and DHET compared with age-matched males. In addition, female OVX C57B/6 mice had greater infarct area and less tissue perfusion following MCAO compared with intact females. No differences were noted between OVX and intact female sEH-knockout mice [64].

Although many of the beneficial effects of $E_{2}$ occur through activation of the serinethreonine kinases Akt and eNOS and the generation of NO, E2's regulation of sEH and EET generation is also protective. In cases of low NO bioavailability due to increased ROS and/ or decreased eNOS expression caused by aging, $\mathrm{E}_{2}$ may attenuate the increased vasoconstriction response through EET generation, which is usually inhibited by NO [65]. However, much work remains to be completed before we can be certain how $\mathrm{E}_{2}$ interacts among sEH and the p450 cytochrome eicosanoid pathway. Recent evidence also suggests that the regulation of the cytochrome p450 pathway is more intricate than believed. Female, but not male, CYP2J5-knockout mice had increased blood pressure and arteriolar vasoconstriction responses to AngII and ET -1 compared with wild-type. Interestingly, female CYP knockout mice also had approximately $50 \%$ decreased serum $\mathrm{E}_{2}$ levels. Invivo $\mathrm{E}_{2}$ replacement attenuated the increase in blood pressure and enhanced constriction response [66]. Potential mechanisms of inter-regulation among $\mathrm{E}_{2}, \mathrm{NO}, \mathrm{NFKB}$ and $\mathrm{sEH}$ are outlined in Figure 3. Although these studies are preliminary, sEH and EETs may emerge as potential therapeutic targets against $\mathrm{CVD}$, and the role of $\mathrm{E}_{2}$ in regulating their effects offers exciting frontiers in cardiovascular endocrinology and pharmacology. 


\section{Estrogen replacement, cardiovascular disease \& aging in women}

Observational studies concluded that postmenopausal oral conjugated equine estrogen (CEE) therapy was associated with a 30-40\% reduced risk of coronary heart disease (CHD), supporting the hypothesis that estrogen prevents heart disease and probably stroke in women [67-69]. This body of evidence translated to the clinical practice of recommending estrogenreplacement therapy to all postmenopausal women. However, major reports from recent large randomized clinical trials have failed to confirm these observations, resulting in a dramatic drop in estrogen therapy use [70-73]. The Heart and Estrogen/progestin Replacement Study (HERS), a secondary prevention trial, demonstrated that postmenopausal women with CHD taking CEE plus progestin (vs placebo) had an excess CHD risk in the first year and no cardiovascular effect after nearly 7 years [70,71]. The Women's Health Initiative (WHI) included two large primary prevention trials in postmenopausal women aged 50-79 years to evaluate CEE alone or CEE plus progestin versus placebo [72,73]. The WHI reported a $23 \%$ increased risk of coronary events with CEE plus progestin and no overall coronary effect with CEE alone. Stroke risk was increased by $31 \%$ with CEE plus progestin and $33 \%$ with CEE alone [72,73].

\section{Timing hypothesis \& subgroup analyses}

Reasons for the apparent discordance between the observational studies and trials are unclear [74]. However, hypotheses include:

- Differences in study populations, including the prevalence of vasomotor symptoms (more prevalent in observational studies), age at enrollment (mean age in trials was $\succeq 63$ vs 30-55 year olds in observational studies), and years since menopause ( $>10$ years in trials vs $<5$ years in observational studies);

- Duration of estrogen therapy (7-8 years in trials vs $10-40$ years in observational studies);

- $\quad$ Age at initiation of estrogen therapy.

The timing hypothesis is related to age at initiation of estrogen therapy and duration of menopause. This hypothesis states that as postmenopausal women age and experience postmenopause longer, they have more existing atherosclerosis and more advanced cardiovascular pathology, are less responsive to the beneficial changes with estrogen therapy and, therefore, draw less cardiovascular benefit from estrogen therapy than younger postmenopausal women (or those who became menopausal more recently) [75]. The initiation of therapy in a more advanced diseased state could lead to a loss of the beneficial effects (Figure 4). In other words, a longer duration between menopause and estrogen therapy use may present an unfavorably low estrogen environment that allows more progression of atherosclerosis and vascular compromise. Beneficial effects of initiating estrogen therapy after such a time interval in postmenopausal women may be overwhelmed by the developed vascular pathology. By contrast, maintaining continuity of a, perhaps, more favorable estrogenic cardiovascular environment after menopause with the use of estrogen therapy could mitigate or postpone such progression.

A recent prospective study over 5 years aimed to test the hypothesis that estrogen therapy use in women recently menopausal (within 5 years) would confer a sex steroid status that would sustain a favorable cardiovascular profile, compared with premenopausal women at midlife [76]. Findings were mixed but not clearly supportive of the timing hypothesis; women taking estrogen therapy within 5 years of menopause had a favorable effect on some but not all lipid indicators and had a less favorable oxidative status and inflammatory response. A separate study of postmenopausal women did not observe that age at menopause or lifetime endogenous estrogen exposure estimation improves cardiovascular risk 
prognostication [77]. Two recent subgroup analyses from the WHI trials support the timing hypothesis in that CEE therapy in women closer to menopause and younger (in their 50s) have beneficial or neutral cardio- and cerebrovascular effects [78,79]. Women aged 50-59 years old had a $45 \%$ reduction in coronary revascularization, a $34 \%$ reduction in myocardial infarction, coronary death or coronary revascularization, no change in stroke risk, and less coronary artery calcification $[78,79]$.

Caution should be taken when interpreting these subgroup analyses since the WHI trials were not designed to conduct these subgroup analyses or to test the timing hypothesis directly. As a result, much debate has ensued regarding the strength of evidence surrounding the timing hypothesis $[80,81]$.

\section{From bench to bedside}

Reconciling results from animal and human studies of estrogen, aging and cardiovascular risks and benefits is a major challenge [82-84]. As described earlier in animal studies, the animal types (and their genetics), animal ages and overall aging models differ across studies. Different estrogen dosage and duration and timing of administration in animal aging models also vary. Cardiovascular aging models in animals function on a timescale (weeks) that is very different from aging in humans (years). For example, it is unknown whether and which aging models in animals compare best to premenopausal women who undergo surgical bilateral ovariectomy (surgical menopause), women who recently underwent natural menopause or women who underwent natural menopause 10 or more years ago. Most animal aging models focus on acute effects of $E_{2}$ administered immediately before, during, or after an induced cardiovascular injury, whereas the large clinical trials study the effects of chronic (many years) estrogen in preventing major cardiovascular injury. Furthermore, the prevention trials tested the effects of CEE, which is biologically different from $\mathrm{E}_{2}$ used in animal studies. These differences in animal and human studies, in addition to the inherent complex actions of estrogen, challenge our ability to draw clear conclusions regarding estrogen's effects in the cardiovascular system and aging, and to derive effective clinical recommendations.

Ongoing clinical trials, including the Early versus Late Intervention Trial with Estradiol (ELITE) and the Kronos Early Estrogen Prevention Study (KEEPS), should provide insight into the validity of the timing hypothesis and the cardiovascular effects of $E_{2}$ [85]. Until new translational evidence emerges, the clinical guidelines regarding CVD risks and benefits suggest that menopausal estrogen therapy is not currently recommended for the prevention of cardiac, cerebrovascular or peripheral thrombotic events and should be discouraged in women with an increased risk of such events $[101,86]$. Estrogen therapy may be appropriate to treat menopausal symptoms or osteoporosis in selected well-defined subgroups of postmenopausal women whose benefits exceed their risks [101]. One such subset could be women who have been postmenopausal for less than 5-10 years for short-term treatment of menopausal symptoms. There is some evidence to support the hypothesis that menopausal symptoms may help to determine whether there are benefits from the use of estrogen therapy. For example, complaints of sweating appear to be associated with lower levels of serum estradiol and greater bone mass loss, while hot flushes correlate with higher oxidative stress markers [87]. However, there are no reports from clinical trials of cardiovascular outcomes specifically in women suffering from menopausal symptoms. However, this area of research to define such subgroups of women is evolving, without current definitive clinical guidelines. 


\section{Future perspective}

Over the next several years, evidence will start to amass to explain the discrepancy between the protective effects of $E_{2}$ in basic sciences and the loss of efficacy against CVD in postmenopausal women. Results from recent clinical trials will shed light on whether the timing hypothesis may explain part of the loss of effect, but so will new emerging roles of $\mathrm{E}_{2}$ in the reduction of inflammation via unknown processes. The emergence of the study of aging will also reveal that much of what we know about $\mathrm{E}_{2}$ and other sex steroids from studies in sexually immature and adult models are not applicable to the aged.

\section{Bibliography}

Papers of special note have been highlighted as:

- of interest

- of considerable interest

1. Mendelsohn ME, Karas RH. Molecular and cellular basis of cardiovascular gender differences. Science. 2005; 308:1583-1587. [PubMed: 15947175]

2. Murphy E, Steenbergen C. Cardioprotection in females: a role for nitric oxide and altered gene expression. Heart Fail Rev. 2007; 12:293-300. [PubMed: 17508281]

3. Choudhry MA, Chaudry IH. 17ß-estradiol: a novel hormone for improving immune and cardiovascular responses following trauma-hemorrhage. J Leukoc Biol. 2008; 83:518-522. [PubMed: 17938275]

40•. Mendelsohn ME, Karas RH. The protective effects of estrogen on the cardiovascular system. N Engl J Med. 1999; 340:1801-1811. An insightful paper summarizing the beneficial effects of 17ß-estradiol (E2) on the cardiovascular system. [PubMed: 10362825]

5. Ferrari AU, Radaelli A, Centola M. Invited review: aging and the cardiovascular system. J Appl Physiol. 2003; 95:2591-2597. [PubMed: 14600164]

6. Taddei S, Virdis A, Mattei P, et al. Aging and endothelial function in normotensive subjects and patients with essential hypertension. Circulation. 1995; 91:1981-1987. [PubMed: 7895356]

7. Chou TC, Yen MH, Li CY, Ding YA. Alterations of nitric oxide synthase expression with aging and hypertension in rats. Hypertension. 1998; 31:643-648. [PubMed: 9461235]

8. Lakatta EG. Arterial and cardiac aging: major shareholders in cardiovascular disease enterprises: part III: cellular and molecular clues to heart and arterial aging. Circulation. 2003; 107:490-497. [PubMed: 12551876]

9. Ruetten H, Zabel U, Linz W, Schmidt HH. Downregulation of soluble guanylyl cyclase in young and aging spontaneously hypertensive rats. Circ Res. 1999; 85:534-541. [PubMed: 10488056]

10. Kloss S, Bouloumie A, Mulsch A. Aging and chronic hypertension decrease expression of rat aortic soluble guanylyl cyclase. Hypertension. 2000; 35:43-47. [PubMed: 10642273]

11. Lin CS, Liu X, Tu R, Chow S, Lue TF. Age-related decrease of protein kinase G activation in vascular smooth muscle cells. Biochem Biophys Res Commun. 2001; 287:244-248. [PubMed: 11549281]

12. Arenas IA, Armstrong SJ, Xu Y, Davidge ST. Tumor necrosis factor-a and vascular angiotensin II in estrogen-deficient rats. Hypertension. 2006; 48:497-503. [PubMed: 16864744]

13. Wassmann S, Baumer AT, Strehlow K, et al. Endothelial dysfunction and oxidative stress during estrogen deficiency in spontaneously hypertensive rats. Circulation. 2001; 103:435-441. [PubMed: 11157697]

14. Widder J, Pelzer T, von Poser-Klein C, et al. Improvement of endothelial dysfunction by selective estrogen receptor-a stimulation in ovariectomized SHR. Hypertension. 2003; 42:991-996. [PubMed: 14581292]

15. Stice JP, Eiserich JP, Knowlton AA. Role of aging vs. the loss of estrogens in the reduction in vascular function in female rats. Endocrinology. 2008 (Epub ahead of print). 
16. Moien-Afshari F, Kenyon E, Choy JC, Battistini B, McManus BM, Laher I. Long-term effects of ovariectomy and estrogen replacement treatment on endothelial function in mature rats. Maturitas. 2003; 45:213-223. [PubMed: 12818467]

17. Liu MY, Hattori Y, Fukao M, Sato A, Sakuma I, Kanno M. Alterations in EDHF-mediated hyperpolarization and relaxation in mesenteric arteries of female rats in long-term deficiency of oestrogen and during oestrus cycle. Br J Pharmacol. 2001; 132:1035-1046. [PubMed: 11226134]

18. Sakuma I, Liu MY, Sato A, et al. Endothelium-dependent hyperpolarization and relaxation in mesenteric arteries of middle-aged rats: influence of oestrogen. Br J Pharmacol. 2002; 135:48-54. [PubMed: 11786479]

19. Lakatta EG. Age-associated cardiovascular changes in health: impact on cardiovascular disease in older persons. Heart Fail Rev. 2002; 7:29-49. [PubMed: 11790921]

20. Alvarez A, Hermenegildo C, Issekutz AC, Esplugues JV, Sanz MJ. Estrogens inhibit angiotensin II-induced leukocyte-endothelial cell interactions in vivo via rapid endothelial nitric oxide synthase and cyclooxygenase activation. Circ Res. 2002; 91:1142-1150. [PubMed: 12480815]

21-. Caulin-Glaser T, Garcia-Cardena G, Sarrel P, Sessa WC, Bender JR. 17 $\beta$-estradiol regulation of human endothelial cell basal nitric oxide release, independent of cytosolic $\mathrm{Ca}^{2+}$ mobilization. Circ Res. 1997; 81:885-892. Demonstrates that $\mathrm{E}_{2}$ activates nitric oxide through nongenomic mechanisms in endothelial cells. [PubMed: 9351464]

22. Cid MC, Schnaper HW, Kleinman HK. Estrogens and the vascular endothelium. Ann NY Acad Sci. 2002; 966:143-157. [PubMed: 12114268]

23. Dubey RK, Jackson EK, Gillespie DG, Zacharia LC, Imthurn B, Keller PJ. Clinically used estrogens differentially inhibit human aortic smooth muscle cell growth and mitogen-activated protein kinase activity. Arterioscler Thromb Vasc Biol. 2000; 20:964-972. [PubMed: 10764660]

24. Zhang Y, Davidge ST. Estrogen replacement increases coronary artery distensibility in ovariectomized rats. Can J Physiol Pharmacol. 1999; 77:75-78. [PubMed: 10535670]

25. Qiu H, Depre C, Ghosh K, et al. Mechanism of gender-specific differences in aortic stiffness with aging in nonhuman primates. Circulation. 2007; 116:669-676. [PubMed: 17664374]

26. Wu JM, Zelinski MB, Ingram DK, Ottinger MA. Ovarian aging and menopause: current theories, hypotheses, and research models. Exp Biol Med (Maywood). 2005; 230:818-828. [PubMed: 16339746]

27. Xu Y, Arenas IA, Armstrong SJ, Davidge ST. Estrogen modulation of left ventricular remodeling in the aged heart. Cardiovasc Res. 2003; 57:388-394. [PubMed: 12566111]

28. Dean SA, Tan J, O'Brien ER, Leenen FH. 17 $\beta$-estradiol downregulates tissue angiotensinconverting enzyme and ANG II type 1 receptor in female rats. Am J Physiol Regul Integr Comp Physiol. 2005; 288:R759-R766. [PubMed: 15550614]

29.. Pedram A, Razandi M, Lubahn D, Liu J, Vannan M, Levin ER. Estrogen inhibits cardiac hypertrophy: role of estrogen receptor- $\beta$ to inhibit calcineurin. Endocrinology. 2008; 149:33613369. Demonstrates that $E_{2}$ could block the development of hypertrophy through estrogen receptor- $\beta$ in a hypertrophic mouse model. [PubMed: 18372323]

30. Pedram A, Razandi M, Aitkenhead M, Levin ER. Estrogen inhibits cardiomyocyte hypertrophy in vitro Antagonism of calcineurin-related hypertrophy through induction of MCIP1. J Biol Chem. 2005; 280:26339-26348. [PubMed: 15899894]

31. Olivetti G, Giordano G, Corradi D, et al. Gender differences and aging: effects on the human heart. J Am Coll Cardiol. 1995; 26:1068-1079. [PubMed: 7560601]

32. Patten RD, Pourati I, Aronovitz MJ, et al. 17ß-estradiol reduces cardiomyocyte apoptosis in vivo and in vitro via activation of phospho-inositide-3 kinase/Akt signaling. Circ Res. 2004; 95:692699. [PubMed: 15345655]

33-. Kim JK, Pedram A, Razandi M, Levin ER. Estrogen prevents cardiomyocyte apoptosis through inhibition of reactive oxygen species and differential regulation of p38 kinase isoforms. J Biol Chem. 2006; 281:6760-6767. Demonstrates that $E_{2}$ inhibits reactive oxygen species production and apoptosis upon hypoxia/reoxygenation through activation of PI3-K and suppression of p38-a in myocytes. [PubMed: 16407188] 
34. Hamilton KL, Lin L, Wang Y, Knowlton AA. Effect of ovariectomy on cardiac gene expression: inflammation and changes in SOCS gene expression. Physiol Genomics. 2008; 32:254-263. [PubMed: 17986523]

35. Jazbutyte V, Hu K, Kruchten P, et al. Aging reduces the efficacy of estrogen substitution to attenuate cardiac hypertrophy in female spontaneously hypertensive rats. Hypertension. 2006; 48:579-586. [PubMed: 16940216]

36. Sharkey LC, Holycross BJ, Park S, et al. Effect of ovariectomy and estrogen replacement on cardiovascular disease in heart failure-prone SHHF/Mcc- fa cp rats. J Mol Cell Cardiol. 1999; 31:1527-1537. [PubMed: 10423350]

37. Roth DA, White CD, Podolin DA, Mazzeo RS. Alterations in myocardial signal transduction due to aging and chronic dynamic exercise. J Appl Physiol. 1998; 84:177-184. [PubMed: 9451633]

38. Muscari C, Giaccari A, Giordano E, Clo C, Guarnieri C, Caldarera CM. Role of reactive oxygen species in cardiovascular aging. Mol Cell Biochem. 1996; 160-161:159-166.

39. Chung HY, Sung B, Jung KJ, Zou Y, Yu BP. The molecular inflammatory process in aging. Antioxid Redox Signal. 2006; 8:572-581. [PubMed: 16677101]

40. Knowlton AA. The role of heat shock proteins in the heart. J Mol Cell Cardiol. 1995; 27:121-131. [PubMed: 7760337]

41. Voss MR, Stallone JN, Li M, Cornelussen RN, Knuefermann P, Knowlton AA. Gender differences in the expression of heat shock proteins: the effect of estrogen. Am J Physiol Heart Circ Physiol. 2003; 285:687-692. First study to demonstrate that estrogen regulates heat-shock protein (HSP) expression and that gender differences in HSPs may partially explain the protective effects of $E_{2}$ in females.

42- Hamilton KL, Gupta S, Knowlton AA. Estrogen and regulation of heat shock protein expression in female cardiomyocytes: cross-talk with NFKB signaling. J Mol Cell Cardiol. 2004; 36:577584. First study to demonstrate that $\mathrm{E}_{2}$ induces expression of HSPs and protects myocytes against hypoxic injury through the NFkB pathway. [PubMed: 15081317]

43. Hamilton KL, Mbai FN, Gupta S, Knowlton AA. Estrogen, heat shock proteins, and NFKB in human vascular endothelium. Arterioscler Thromb Vasc Biol. 2004; 24:1628-1633. [PubMed: 15231513]

44. Stice JP, Knowlton AA. Estrogen, NFkB, and the heat shock response. Mol Med. 2008; 14:517527. [PubMed: 18431462]

45. Bongrazio M, Comini L, Gaia G, Bachetti T, Ferrari R. Hypertension, aging, and myocardial synthesis of heat-shock protein 72. Hypertension. 1994; 24:620-624. [PubMed: 7960023]

46. Demirel HA, Hamilton KL, Shanely RA, Tumer N, Koroly MJ, Powers SK. Age and attenuation of exercise-induced myocardial HSP72 accumulation. Am J Physiol Heart Circ Physiol. 2003; 285:H1609-H1615. [PubMed: 12791594]

47. Leger JP, Smith FM, Currie RW. Confocal microscopic localization of constitutive and heat shockinduced proteins HSP70 and HSP27 in the rat heart. Circulation. 2000; 102:1703-1709. [PubMed: 11015351]

48. Chiamvimonvat N, Ho CM, Tsai HJ, Hammock BD. The soluble epoxide hydrolase as a pharmaceutical target for hypertension. J Cardiovasc Pharmacol. 2007; 50:225-237. [PubMed: 17878749]

49. Yu Z, Xu F, Huse LM, et al. Soluble epoxide hydrolase regulates hydrolysis of vasoactive epoxyeicosatrienoic acids. Circ Res. 2000; 87:992-998. [PubMed: 11090543]

50. Inceoglu B, Schmelzer KR, Morisseau C, Jinks SL, Hammock BD. Soluble epoxide hydrolase inhibition reveals novel biological functions of epoxyeicosatrienoic acids (EETs). Prostaglandins Other Lipid Mediat. 2007; 82:42-49. [PubMed: 17164131]

51. Imig JD, Zhao X, Capdevila JH, Morisseau C, Hammock BD. Soluble epoxide hydrolase inhibition lowers arterial blood pressure in angiotensin II hypertension. Hypertension. 2002; 39:690-694. [PubMed: 11882632]

52. Fornage M, Lee CR, Doris PA, et al. The soluble epoxide hydrolase gene harbors sequence variation associated with susceptibility to and protection from incident ischemic stroke. Hum Mol Genet. 2005; 14:2829-2837. [PubMed: 16115816] 
53. Node K, Huo Y, Ruan X, et al. Anti-inflammatory properties of cytochrome P450 epoxygenasederived eicosanoids. Science. 1999; 285:1276-1279. [PubMed: 10455056]

54. Kozak W, Kluger MJ, Kozak A, Wachulec M, Dokladny K. Role of cytochrome P-450 in endogenous antipyresis. Am J Physiol Regul Integr Comp Physiol. 2000; 279:R455-R460. [PubMed: 10938232]

55. Seubert JM, Sinal CJ, Graves J, et al. Role of soluble epoxide hydrolase in postischemic recovery of heart contractile function. Circ Res. 2006; 99:442-450. [PubMed: 16857962]

56. Xu D, Li N, He Y, et al. Prevention and reversal of cardiac hypertrophy by soluble epoxide hydrolase inhibitors. Proc Natl Acad Sci USA. 2006; 103:18733-18738. [PubMed: 17130447]

57. Zhang W, Koerner IP, Noppens R, et al. Soluble epoxide hydrolase: a novel therapeutic target in stroke. J Cereb Blood Flow Metab. 2007; 27:1931-1940. [PubMed: 17440491]

58. Gschwendtner A, Ripke S, Freilinger T, et al. Genetic variation in soluble epoxide hydrolase (EPHX2) is associated with an increased risk of ischemic stroke in white Europeans. Stroke. 2008; 39:1593-1596. [PubMed: 18323494]

59. Lee CR, North KE, Bray MS, et al. Genetic variation in soluble epoxide hydrolase (EPHX2) and risk of coronary heart disease The Atherosclerosis Risk in Communities (ARIC) study. Hum Mol Genet. 2006; 15:1640-1649. [PubMed: 16595607]

60. Wei Q, Doris PA, Pollizotto MV, et al. Sequence variation in the soluble epoxide hydrolase gene and subclinical coronary atherosclerosis: interaction with cigarette smoking. Atherosclerosis. 2007; 190:26-34. [PubMed: 16545818]

61. Fornage M, Boerwinkle E, Doris PA, Jacobs D, Liu K, Wong ND. Polymorphism of the soluble epoxide hydrolase is associated with coronary artery calcification in African-American subjects: The Coronary Artery Risk Development in Young Adults (CARDIA) study. Circulation. 2004; 109:335-339. [PubMed: 14732757]

62. Fornage M, Hinojos CA, Nurowska BW, et al. Polymorphism in soluble epoxide hydrolase and blood pressure in spontaneously hypertensive rats. Hypertension. 2002; 40:485-490. [PubMed: 12364351]

63-. Koerner IP, Zhang W, Cheng J, Parker S, Hurn PD, Alkayed NJ. Soluble epoxide hydrolase: regulation by estrogen and role in the inflammatory response to cerebral ischemia. Front Biosci. 2008; 13:2833-2841. First study to demonstrate that $\mathrm{E}_{2}$ regulates soluble epoxide hydrolase expression and partially attenuates inflammation through the cytochrome p450 eicosanoid pathway. [PubMed: 17981757]

64. Zhang, W.; Hurn, PD.; Alkayed, NJ. Selective targeting of soluble epoxide hydrolase for neuroprotection in hormone-depleted female brain. Program and abstracts of the Society of Neuroscience Meeting; San Diego, CA, USA. 3-7 November, 2007; (Abstract 376 9)

65. Fleming I. Cytochrome p450 and vascular homeostasis. Circ Res. 2001; 89:753-762. [PubMed: 11679404]

66. Athirakul K, Bradbury Dagger JA, Graves JP, et al. Increased blood pressure in mice lacking cytochrome P450 2J5. FASEB J. 2008 (Epub ahead of print).

67. Barrett-Connor E, Bush TL. Estrogen and coronary heart disease in women. JAMA. 1991; 265:1861-1867. [PubMed: 2005736]

68. Grady D, Rubin SM, Petitti DB, et al. Hormone therapy to prevent disease and prolong life in postmenopausal women. Ann Intern Med. 1992; 117:1016-1037. [PubMed: 1443971]

69. Barrett-Connor E, Grady D. Hormone replacement therapy, heart disease, and other considerations. Annu Rev Public Health. 1998; 19:55-72. [PubMed: 9611612]

70-. Hulley S, Grady D, Bush T, et al. Randomized trial of estrogen plus progestin for secondary prevention of coronary heart disease in postmenopausal women. Heart and Estrogen/progestin Replacement Study (HERS) Research Group. JAMA. 1998; 280:605-613. This pivotal study was the first to demonstrate that initiating hormone-replacement therapy (HRT) in postmenopausal women with coronary disease offered no cardiovascular benefit and increased the risk from stroke. [PubMed: 9718051]

71. Grady D, Herrington D, Bittner V, et al. Cardiovascular disease outcomes during 6.8 years of hormone therapy: Heart and Estrogen/progestin Replacement Study follow-up (HERS II). JAMA. 2002; 288:49-57. [PubMed: 12090862] 
72-. Rossouw JE, Anderson GL, Prentice RL, et al. Risks and benefits of estrogen plus progestin in healthy postmenopausal women: principal results from the Women's Health Initiative randomized controlled trial. JAMA. 2002; 288:321-333. Landmark study demonstrating that HRT in healthy postmenopausal women increases the risk for cardiovascular disease, stroke and breast cancer. [PubMed: 12117397]

73. Anderson GL, Limacher M, Assaf AR, et al. Effects of conjugated equine estrogen in postmenopausal women with hysterectomy: the Women's Health Initiative randomized controlled trial. JAMA. 2004; 291:1701-1712. [PubMed: 15082697]

74. Hodis HN. Assessing benefits and risks of hormone therapy in (2008): new evidence, especially with regard to the heart. Cleve Clin J Med. 2008; 75(Suppl 4):S3-S12. [PubMed: 18697261]

75. Turgeon JL, Carr MC, Maki PM, Mendelsohn ME, Wise PM. Complex actions of sex steroids in adipose tissue, the cardiovascular system, and brain: insights from basic science and clinical studies. Endocr Rev. 2006; 27:575-605. Also available at: http://edrv.endojournals.org/cgi/reprint/ 27/6/575. [PubMed: 16763155]

76. Sowers MR, Randolph J Jr, Jannausch M, Lasley B, Jackson E, McConnell D. Levels of sex steroid and cardiovascular disease measures in premenopausal and hormone-treated women at midlife: implications for the 'timing hypothesis'. Arch Intern Med. 2008; 168:2146-2153. [PubMed: 18955645]

77. Atsma F, van der Schouw YT, Grobbee DE, Hoes AW, Bartelink ML. No added value of age at menopause and the lifetime cumulative number of menstrual cycles for cardiovascular risk prediction in postmenopausal women. Int J Cardiol. 2008; 130:190-195. [PubMed: 18063146]

78. Rossouw JE, Prentice RL, Manson JE, et al. Postmenopausal hormone therapy and risk of cardiovascular disease by age and years since menopause. JAMA. 2007; 297:1465-1477. [PubMed: 17405972]

79. Manson JE, Allison MA, Rossouw JE, et al. Estrogen therapy and coronary-artery calcification. N Engl J Med. 2007; 356:2591-2602. [PubMed: 17582069]

80. Manson JE, Bassuk SS. Invited commentary: hormone therapy and risk of coronary heart disease why renew the focus on the early years of menopause? Am J Epidemiol. 2007; 166:511-517. [PubMed: 17646204]

81. Barrett-Connor E. Hormones and heart disease in women: the timing hypothesis. Am J Epidemiol. 2007; 166:506-510. [PubMed: 17849510]

82. Wise PM. Estrogens and cerebrovascular stroke: what do animal models teach us? Ann NY Acad Sci. 2005; 1052:225-232. [PubMed: 16024765]

83. Wise PM. Estrogen therapy: does it help or hurt the adult and aging brain? Insights derived from animal models. Neuroscience. 2006; 138:831-835. [PubMed: 16310320]

84m. Turgeon JL, McDonnell DP, Martin KA, Wise PM. Hormone therapy: physiological complexity belies therapeutic simplicity. Science. 2004; 304:1269-1273. Insightful examination of the actions of $E_{2}$ and progestin, along with an analysis of the recent clinical trial findings and implications for HRT. [PubMed: 15166356]

85. Harman SM, Brinton EA, Cedars M, et al. KEEPS: The Kronos Early Estrogen Prevention Study. Climacteric. 2005; 8:3-12. [PubMed: 15804727]

86. Estrogen and progestogen use in peri- and postmenopausal women: March (2007) position statement of the North American Menopause Society. Menopause. 2007; 14:168-182. [PubMed: 17259911]

87. van der Schouw YT, Grobbee DE. Menopausal complaints, oestrogens, and heart disease risk: an explanation for discrepant findings on the benefits of post-menopausal hormone therapy. Eur Heart J. 2005; 26:1358-1361. [PubMed: 15860515]

\section{Website}

101. American Association of Clinical Endocrinologists (AACE) position statement on hormone replacement therapy (HRT) and cardiovascular risk. 2008. www.aace.com/pub/pdf/guidelines/ HRTCVRISKposition_statement.pdf 


\section{Executive summary}

\section{Vascular aging}

- Vasorelaxation is impaired with age, which is thought to be due to the nitric oxide (NO)-mediated response to acetylcholine.

- Loss of $17 \beta$-estradiol $\left(\mathrm{E}_{2}\right)$ can also impair vasorelaxation by decreasing the $\mathrm{NO}$ receptor soluble guanylyl cyclase.

- Changes in extracellular matrix composition (ECM) may also impair vascular function by stiffening vessel walls.

\section{Estrogen \& the myocardium}

- $\mathrm{E}_{2}$ plays a protective role in cardiomyocytes.

- Ovariectomy (OVX) can increincrease the expression of genes involved in inflammation, ECM formation and apoptosis.

- OVX can decrease the expression of genes involved in vascular tone and adhesion.

- Specific animal models suggest that OVX can increase signs of hypertrophy, while $\mathrm{E}_{2}$ replacement in adult $\mathrm{OVX}$ models can abrogate them.

\section{Stress response, aging \& estrogen}

- The aging myocardium shows an altered stress response.

- $\mathrm{E}_{2}$ treatment can activate the cytoprotective $\mathrm{NF} \kappa \mathrm{B}$ in aged rats in the short term, but inhibit it in the long term.

- $\mathrm{E}_{2}$ treatment can increase heat-shock protein expression in adult, but not aged rats.

\section{$E_{2}$, soluble epoxide hydrolase \& cardiovascular injury}

- Soluble epoxide hydrolase (sEH) can decrease the expression of the beneficial epoxyeicosatrienoic acids (EETs).

- EETs can inhibit NFKB activation; therefore, increasing EET levels (by blocking $\mathrm{sEH}$ ) could override the $\mathrm{NF \kappa B}$ activation by $\mathrm{E}_{2}$, causing the long-term inhibition seen with $\mathrm{E}_{2}$.

- $\mathrm{E}_{2}$ may also directly suppress $\mathrm{sEH}$ and may help to attenuate inflammation.

\section{Estrogen replacement, cardiovascular disease \& aging in women}

- The HERS and WHI studies showed an increase risk of cardiovascular disease (CVD) in postmenopausal women taking hormone-replacement therapy (HRT).

- Studies only looked at older women who were already well past menopause and thus had no endogenous hormones for some time.

- The time hypothesis suggests that vessels were already damaged in these women, and hormones could not repair damage or prevent more.

- $\quad$ HRT for younger women (peri- or just post-menopausal) could prevent CVD.

- The ELITE and KEEPS studies should determine the effectiveness of earlier HRT on CVD. 


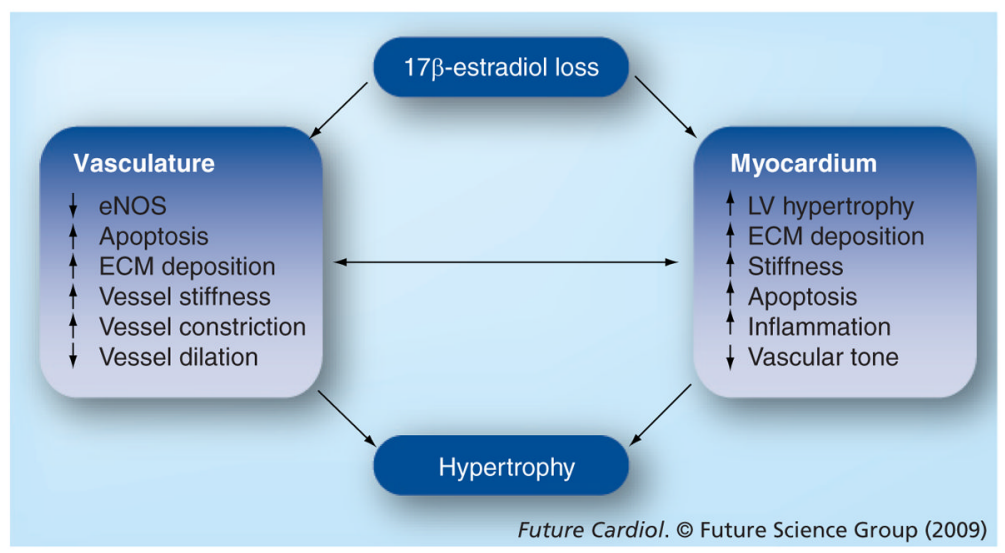

Figure 1. Cardiovascular changes induced with ovariectomy in adult animal models In the vasculature, ovariectomy (OVX) leads to increased vessel stiffness, ECM deposition, endothelial cell apoptosis, and sensitivity to vasocontrictive agents. OVX also leads to decreased expression and activity of eNOS and vasodilatory responses. In the myocardium, OVX decreases vascular tone, increases inflammation, myocardial stiffness, ECM deposition, apoptosis and can lead to LV hypertrophy.

ECM: Extracellular matrix; eNOS: Endothelial nitric oxide synthase; LV: Left ventricular. 


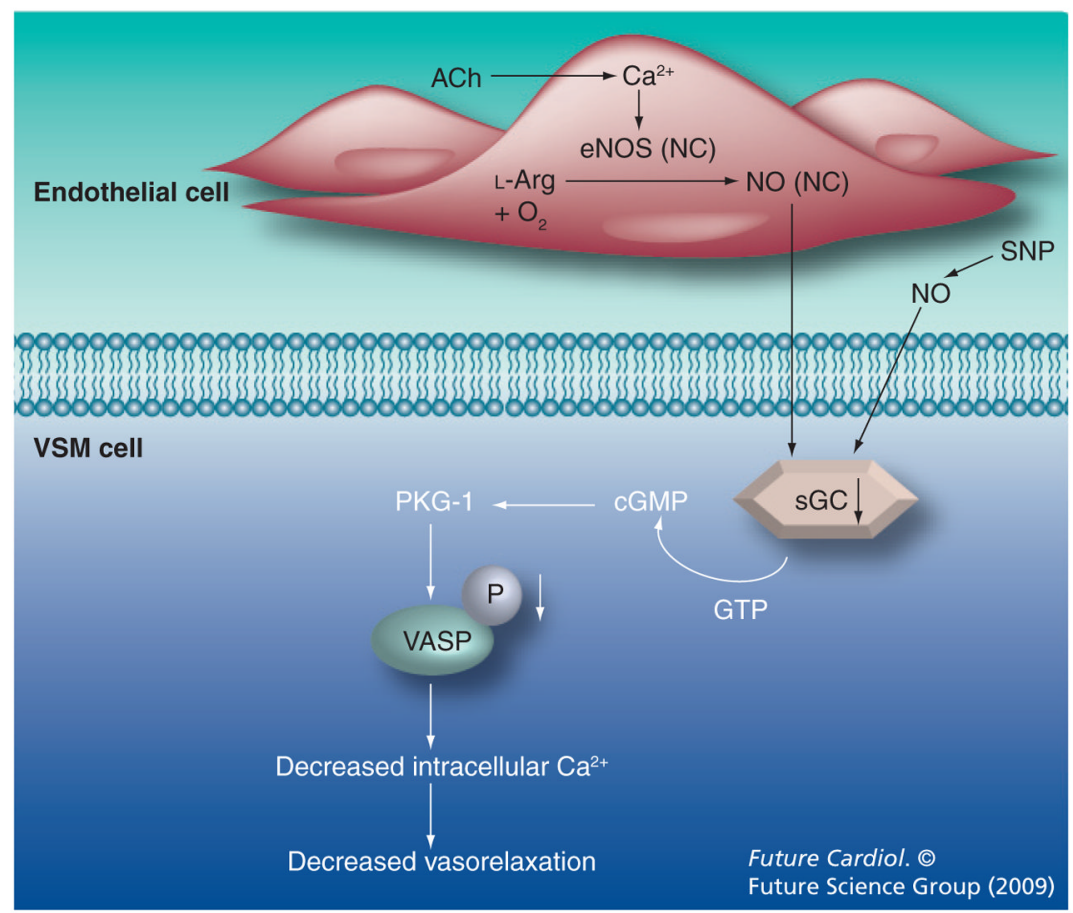

Figure 2. Changes in the endothelium and vascular smooth muscle in aged ovariectomized Norway Brown rats

NO is generated from L-arginine in the endothelium where it diffuses into the VSM and binds to the NO receptor, sGC. sGC converts GTP to cGMP, and activates a cascade of cGMP-dependant protein kinase and VASP. This results in a decrease in intracellular $\mathrm{Ca}^{2+}$ levels and vasorelaxation. Aged ovariectomy Norway Brown rats had no change in eNOS or NO, but decreased expression of sGC and decreased activation of VASP, leading to impaired relaxation in response to acetylcholine and sodium nitroprusside. $\mathrm{E}_{2}$ replacement attenuated these changes.

eNOS: Endothelial NO synthase; NC: No change: NO: Nitric oxide; sGC: Soluble guanylyl cyclase; VASP: Vasodilator-stimulated phosphoprotein; VSM: Vascular smooth muscle. 


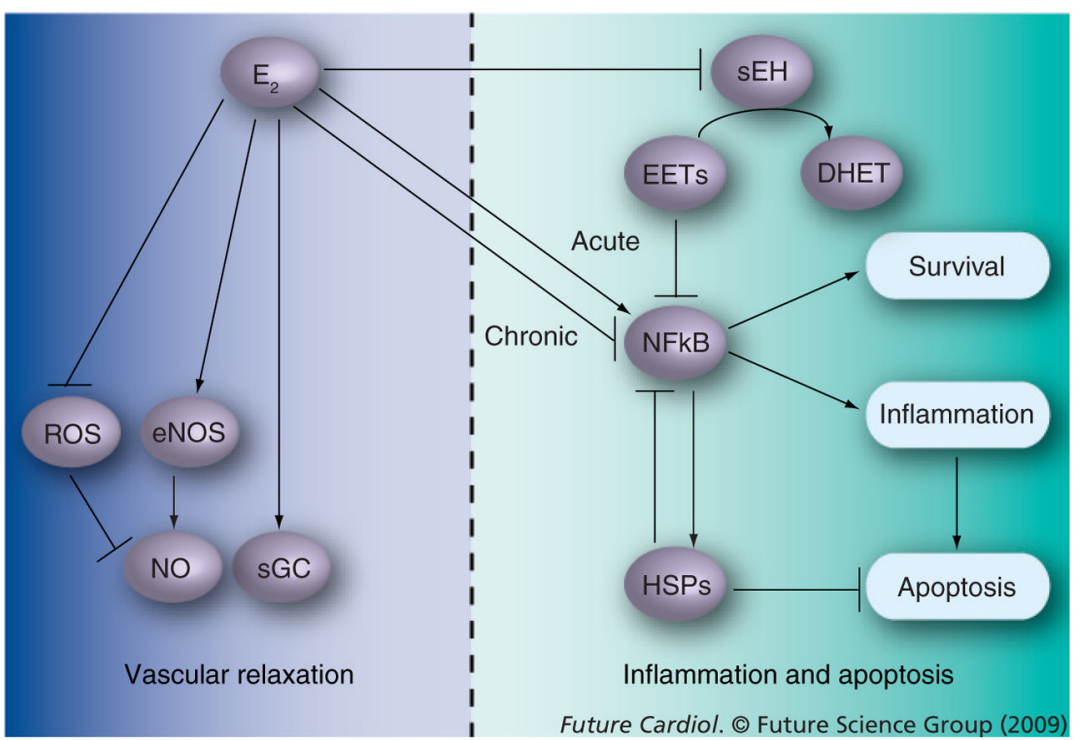

Figure 3. Role of $\mathbf{E}_{2}$, epoxide hyrolase and $\mathrm{NF}_{k} \mathrm{~B}$ in the cardiovascular system

$17 \beta$-estradiol can increase vascular relaxation through the activation of eNOS and increased bioavailability of NO or upregulation of the NO receptor, soluble guanylyl cyclase. In addition, $\mathrm{E}_{2}$ suppresses ROS formation, which can decrease NO bio-availability through free-radical formation. $\mathrm{NF} \kappa \mathrm{B}$ activation induces heat-shock proteins, antiapoptotic proteins and inflammatory processes. While acute $\mathrm{NF \kappa B}$ activation is protective, chronic activation leads to sustained inflammation and apoptosis. $\mathrm{E}_{2}$ is unique in that it acutely activates $\mathrm{NF \kappa B}$ to protect cells from short-term stress, but long-term $\mathrm{E}_{2}$ treatment suppresses NFkB activation to protect cells from death. The expression of soluble epoxide hyrolase, which converts epoxyeico-satrienoic acids into dihydroxyeicosatrienoic acids, can potentially be inhibited by $\mathrm{E}_{2}$, thus allowing an additional mechanism to block long-term $\mathrm{NF \kappa B}$ activation. $E_{2}$ : 17ß-estradiol; EET: Epoxyeicosatrienoic acid; eNOS: Endothelial NO synthase; DHET: Dihydroxyeicosatrienoic acid; ROS: Reactive oxygen species; sEH: Epoxide hydrolase; NO: Nitric oxide. 


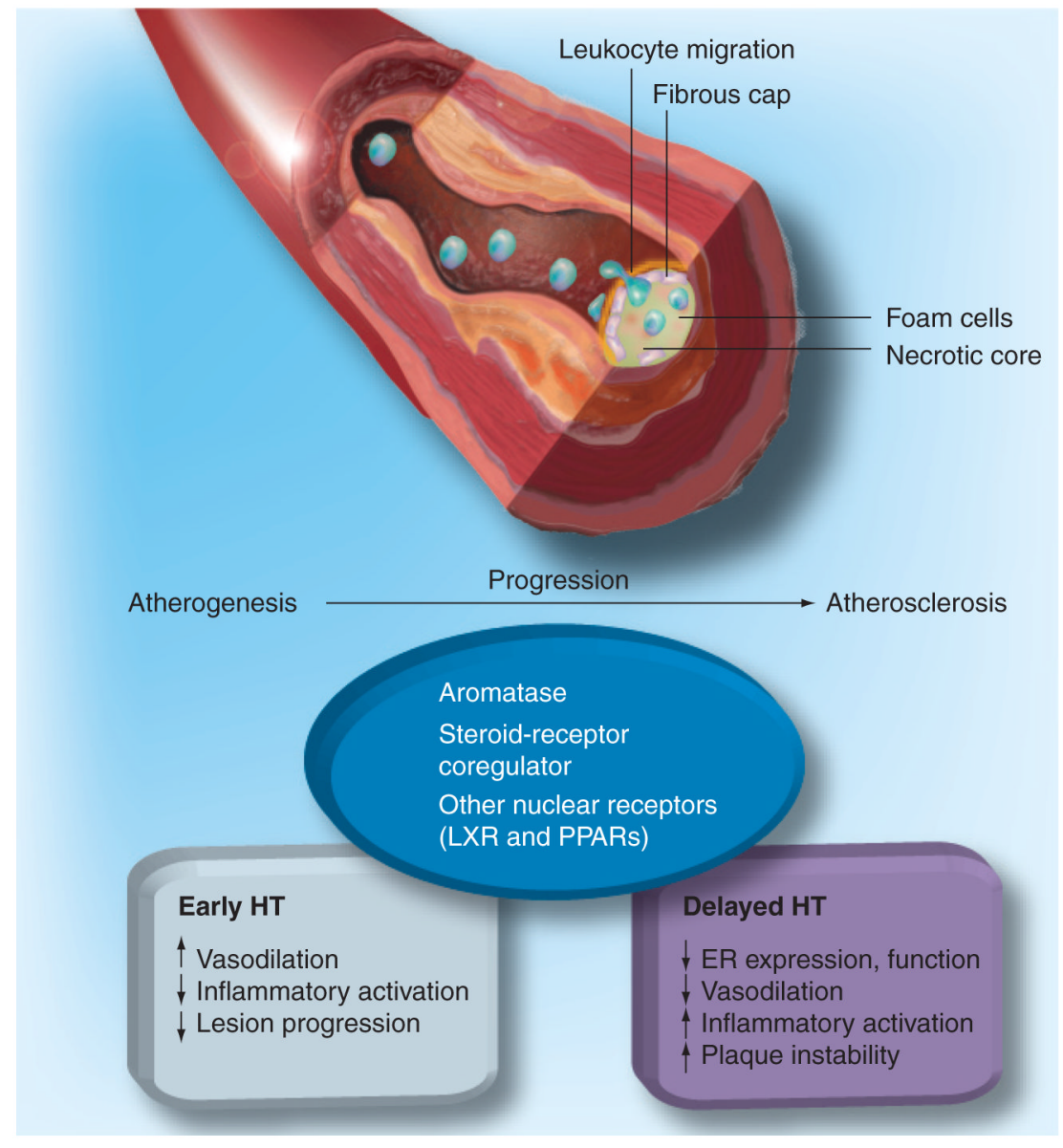

Figure 4. Altered vascular responsiveness to hormone therapy with age

The efficacy and effect of HT changes based on the stage of atherosclerotic disease and timing HT is initiated. As the disease state of atherosclerosis progresses the beneficial effects of early HT (increased vasodilation and decreased inflammatory activation and lesion progression) are replaced by more deleterious delayed HT effects. In the setting of advanced atherosclerotic disease, estrogens are less effective due to decreased estrogen-receptor expression and function, which leads to decreased vasodilation, increased inflammation and plaque instability. The roles that other steroid receptors and coregulators in the vasculature play in nuclear receptor signaling are less understood.

HT: Hormone therapy; LXR: Liver X receptor; PPAR: Peroxisome proliferator-activated receptors

Reproduced with permission from [75], () The Endocrine Society (2008). 